\title{
Cloning of acetyl-CoA acetyltransferase gene from Halomonas elongata BK-AG18 and in silico analysis of its gene product
}

\author{
Ni Putu Yuliastri ${ }^{1}$, Enny Ratnaningsih ${ }^{1}$, and Rukman Hertadi ${ }^{1, *}$ \\ ${ }^{1}$ Biochemistry Research Division, Department of Chemistry, Institut Teknologi Bandung, Jalan Ganesha 10, Bandung 40132, West Java, \\ Indonesia \\ *Corresponding author: rukman@chem.itb.ac.id
}

\begin{abstract}
Polyhydroxybutyrate (PHB) is a biodegradable polymer that can be used as a substitute for petrochemical plastics. Bacteria accumulate PHB in their cells as carbon and energy reserves because of unbalanced growth conditions. This study aimed to amplify phbA from the chromosomal DNA of Halomonas elongata BK-AG18, a PHB-producing bacterium that was previously isolated from the Bledug Kuwu mud crater of Central Java, Indonesia. The obtained phbA amplicon was 1176 bp. This fragment was cloned into a pGEM-T Easy cloning vector and used to transform Eschericia coli TOP10. The recombinant colonies were selected using blue-white screening, confirmed by size screening, reconfirmed by re-PCR, and sequenced. When putative $p h b A$ sequences were aligned with $H$. elongata DSM2581 chromosome using BLASTN, this sequence showed $99 \%$ identity. The deduced amino acid sequences of this clone showed $100 \%$ identity to PhbA of $H$. elongata DSM2581, suggesting that the obtained cloned fragment is a phbA gene. The 3D structure predicted by I-TASSER showed that PhbA of H. elongata BK-AG18 had a high similarity to the acetyl CoA acetyltransferase structure of Ralstonia eutropha H16. PhbA of H. elongata BK-AG18 possesses three catalytic residues, namely Cys88, His348, and Cys378.
\end{abstract}

KEYWORDS acetyl-CoA acetyltransferase; Halomonas elongata BK-AG18; polyhydroxybutyrate

\section{Introduction}

Plastic materials are widely used for various human activities. This massive plastic usage has caused serious environmental problems because of their non-biodegradability (Singh 2014). Common plastics are manufactured from non-renewable fossil fuels and their increasing demand will speed up fossil fuel depletion (Colwill et al. 2012). Therefore, the alternative and more environmentally friendly plastics are needed. Polyhydroxyalkanoates (PHAs) are biodegradable polymers that can be used as plastics, synthesized and accumulated by bacteria as intracellular carbon storage granules in response to nutrient limitations (Dietrich et al. 2013). Polyhydroxybutyrate (PHB) is the most common type of PHA that accumulating in bacteria and archaeal cells (Muangsuwan et al. 2015).

The biosynthetic pathway of PHB in bacteria includes three reactions catalyzed by three different enzymes, namely acetyl-CoA acetyltransferase, beta-ketoacyl-ACP reductase, and PHB polymerase. The acetyl-CoA acetyltransferase, encoded by phbA gene, catalyzes the condensation of acetyl-CoA molecules to produce acetoacetylCoA molecule. Beta-ketoacyl-ACP reductase, encoded by $p h b B$ gene, reduces acetoacetyl-CoA to (R)3-hydroxybutyryl-CoA. On the other hand, PHB poly- merase, encoded by phbC gene, polymerizes the (R)-3hydroxybutyryl-CoA monomers to form PHB (Jari et al. 2015). Halomonas elongata BK-AG18 isolated from Bledug Kuwu, Central Java, Indonesia was known to produce detectable PHB (Hertadi et al. 2017). In this study, the phbA gene was isolated from this strain and cloned into a pGEM-T Easy vector in Escherichia coli TOP10.

\section{Materials and methods}

\subsection{Bacterial strain, plasmid, and chemicals}

H. elongata BK-AG18 local strain was used as a source of chromosomal DNA. E. coli TOP10 was used as the host strain for gene cloning. These bacteria were obtained from the Biochemistry Laboratory of the Institut Teknologi Bandung. The pGEM-T Easy (Promega) was used as cloning vector. Oligonucleotide primers were ordered from Macrogen, South Korea. KAPA Taq Ready Mix PCR Kit, T4 DNA ligase and DNA ladder were purchased from Promega. Sodium chloride from Amresco and yeast extract, tryptone, bacto agar from Deben Diagnostics Ltd. were used as Luria-Bertani medium's ingredients. Ampicillin and tetracyclin from Bioline were used as antibiotics to screen a recombinant clone. Isopropyl- 


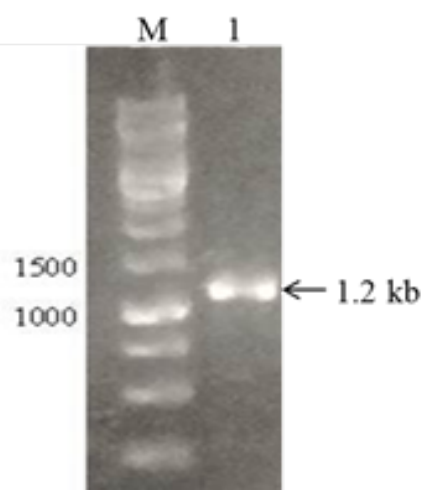

FIGURE 1 Electropherogram of PCR result. M: Generuler $1 \mathrm{~kb}$ DNA Ladder, 1: phbA amplicon. The obtained amplicon size was approximately $1.2 \mathrm{~kb}$ which is similar to the size of the $p h b A$ gene from $\mathrm{H}$. elongata DSM2581 from GenBank.

$\beta$-D-galactopyranoside (IPTG) and 5-bromo-4-chloro-3indoyl- $\beta$-D-galactoside from Promega were also used to screen positive recombinant clones.

\subsection{Primer design}

The $p h b A$ primers were designed based on $p h b A$ full nucleotide sequences from $H$. elongata DSM2581 in GenBank database by the authors. Some forward and reverse primer candidates were designed and the parameters of \% GC, Tm, the absence of hairpin, dimer, and loop structure were analyzed using Oligo Analyzer. Fast PCR was performed to see the mispriming probability.

\subsection{Culturing condition, genomic DNA isolation and amplification of phbA gene}

$H$. elongata BK-AG18 was grown in a modified high glucose medium (HM) as described by Hertadi et al. (2017). Chromosomal DNA of H. elongata BK-AG18 was isolated using Klijn method (Klijn et al. 1991). Amplification of phbA gene was carried out by PCR by the folowing primers: phbAF(5'ATGTCAGAAGTGGTGATCGTC-3') as forward primer and phbAR (5'-TCAGCGCTCGATGGCCAG-3') as re- verse primer. PCR were conducted on an automatic thermal cycler (BIORAD) for one cycle predenaturation at $95^{\circ} \mathrm{C}$ for $4 \mathrm{~min}, 34$ cycles of denaturation at $94^{\circ} \mathrm{C}$ for 30 $\mathrm{s}$, annealing at $61^{\circ} \mathrm{C}$ for $30 \mathrm{~s}$, and extension at $72^{\circ} \mathrm{C}$ for $90 \mathrm{~s}$. The reaction was completed by final extension at $72^{\circ} \mathrm{C}$ for $5 \mathrm{~min}$. The $p h b A$ amplicon was confirmed by electrophoresis on $1 \%(\mathrm{w} / \mathrm{v})$ agarose gel.

\subsection{Cloning and recombinant clone selection}

The amplicon of phbA gene was ligated into pGEM-T Easy using T4 DNA ligase and transformed into competent E.coli TOP10 cells using heat shock method (Sambrook and Russell 2001). The transformants were bluewhite selected on Luria Bertani solid medium supplemented with100 $\mu \mathrm{g} / \mathrm{ml}$ ampicillin, $20 \mathrm{ug} / \mathrm{ml} \mathrm{X-gal,} \mathrm{and} 0.1$ M IPTG. The recombinant plasmids were confirmed by size screening and re-PCR. Recombinant plasmids DNA were isolated from the transformants with Geneaid High Speed Plasmid Mini Kit (Geneaid Biotech Ltd., Taiwan).

\subsection{Sequencing of phbA gene}

Determination of $p h b A$ nucleotide sequences was performed by 1stBASE, Malaysia with dye terminator dideoxy Sanger Method using universal primer of T7 and SP6 promoter.

\subsection{Catalytic residues and three dimensional struc- ture prediction of PhbA}

PhbA amino acid sequence was deduced from $p h b A$ gene sequences. Prediction of PhbA catalytic residues was performed using Sequence Annotated by Structure (SAS) and Catalytic Site Atlas (CSA). On the other hand, the prediction of PhbA 3D structure was conducted using ITASSER.

\section{Results and discussion}

\subsection{Chromosome isolation and gene amplification}

The chromosome of $H$. elongata BK-AG18 was successfully isolated. Using this chromosome and the designed

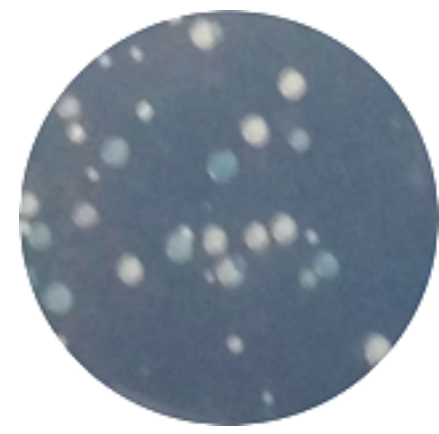

(a)

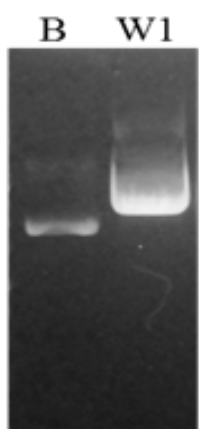

(b)

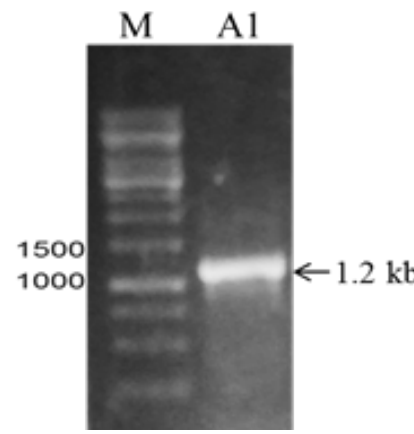

(c)

FIGURE 2 Selection of recombinant clones. (a) Blue-white screening of E.coli TOP10 transformants, (b) Size screening of recombinant clones, B: plasmid from blue colony, W1: recombinant plasmid from white colony. (c) re-PCR of phbA gene in pGEM-phbA, M: Generuler 1 kb DNA Ladder, A1: phbA amplicon from W1. 


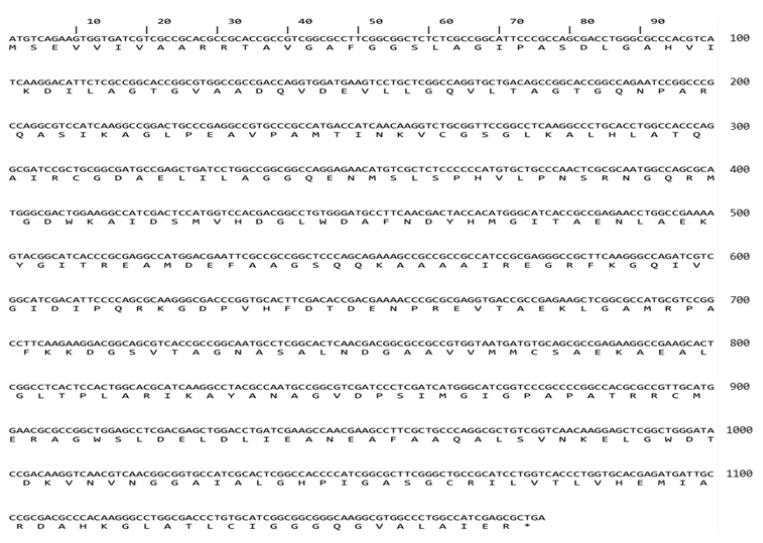

FIGURE 3 The nucleotide sequences of $p h b A$ gene and its deduced amino acid sequences.

primers, the performed PCR reaction has produced a $p h b A$ gene as shown by a single band of the amplicon on agarose gel electrophoresis (Figure 1).

\subsection{Cloning and recombinant clone selection}

The $1.2 \mathrm{~kb}$ obtained amplicon was inserted into the pGEM$\mathrm{T}$ Easy vector and transformed into E.coli TOP10. The transformants will survive in LB-ampicillin medium, and the recombinant clones will appear as white colonies. On the other hand, the transformants with plasmid without insert will appear as blue colonies (Figure 2a). The positive recombinant clones were confirmed by size screening (Figure 2b) and re-PCR (Figure 2c). As presented in Figure $2 \mathrm{~b}$ and $2 \mathrm{c}$, the recombinant plasmid has larger size compared to the non-recombinant plasmid and the re-PCR produces $1.2 \mathrm{~kb}$ fragment as expected.

\subsection{Sequencing of phbA gene in $p G E M-p h b A$}

The sequence of $1176 \mathrm{bp} p h b A$ gene and its deduced amino acids is shown in Figure 3. The BLASTN analysis indicated that this phbA gene showed 99\% identity with the whole genome of $H$. elongata DSM2581 (Figure 4a). The BLASTP analysis on the deduced amino acid of this gene, PhbA, showed $100 \%$ identity with acetyl-CoA acetyltrans-

\begin{tabular}{|c|c|c|c|c|}
\hline \multicolumn{5}{|l|}{ ii Alignments :Download $\times$ GenBank Graphics Distance tree of resulls } \\
\hline Description & $\begin{array}{l}\text { Query } \\
\text { cover }\end{array}$ & $\begin{array}{c}E \\
\text { value }\end{array}$ & Ident & Accession \\
\hline (1) Halomonas elongata OS:1 2581, complete genome. & $100 \%$ & 0.0 & $99 \%$ & FN8695682 \\
\hline 0 Haldamina sedminis strain Hb3 complete genome & $99 \%$ & 0.0 & $88 \%$ & CP018139.1 \\
\hline Q Halomonasso. 1513 . complete genome & $99 \%$ & 0.0 & $85 \%$ & CP0193261 \\
\hline 0 Halomonas chromatireducens stra in AGD 8-3, complete genome & $98 \%$ & 0.0 & $85 \%$ & CP014226.1 \\
\hline (1) Cobetia marina strain JCM 21022 . complete genome & $99 \%$ & 0.0 & $83 \%$ & CP0171141 \\
\hline (1) Halomonas SO R.57.5 genome assembly HalomonasR57.5 chromosome: 1 & $99 \%$ & 0.0 & $81 \%$ & LN8130191 \\
\hline (1) Halomonasso KO116, complete genome. & $98 \%$ & 0.0 & $81 \%$ & CP0110521 \\
\hline
\end{tabular}

(a) ferase from $H$. elongata DSM2581 (Figure 4b).

Literature studies stated that PhbA super family contains three catalytic residues: Cys89, His348, and Cys378 as shown in Zooglea ramigera (Modis and Wierenga 2000).The PhbA-deduced amino acids from $H$. elongata BK-AG18 also has Cys88, His348, and Cys378, confirming that the isolated gene is $p h b A$. The PhbA 3D structure predicted by I-TASSER showed $68.72 \%$ identity to acetylCoA acetyltransferase structure from Ralstonia eutropha H16 (RePhbA). The modelling 3D structure of PhbA predicted by I-TASSER with its catalytic residues can be seen in Figure 5.

In RePhbA, Cys89 has a function as covalent catalyst, His349 as general base, while Cys378 was a second nucleophile (Kim and Kim 2014). The superposition showed that Cys88, His348 and Cys379 residues in our PhbA structure have the same positions with Cys89, His349 and Cys378 from RePhbA.

\section{Conclusions}

The designed primers had successfully amplified phbA gene that code acetyl-CoA acetyltransferase from $H$. elongata BK-AG18 chromosomal DNA. This phbA gene showed $99 \%$ identity to the whole genome of $H$. elongata DSM2581. The deduced amino acid sequences of this gene showed $100 \%$ identity with acetyl-CoA acetyltransferase of $H$. elongata DSM2581.The three amino acid on PhbA catalytic sites are Cys88, His348, and Cys378 which is similar to the PhbA catalytic sites of Zooglea ramigera, confirming that the phbA gene isolated is coding for PhbA protein superfamily.

\section{Acknowledgements}

This research was funded by Indonesia Endowment Fund for Education (LPDP), ITB research grant, and the university priority research grant with the contract number: 310u/11.C01/PL/2016/ awarded to RH.

\begin{tabular}{|c|c|c|c|c|c|}
\hline \multicolumn{6}{|c|}{ 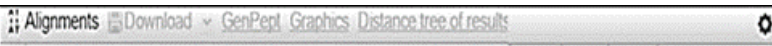 } \\
\hline \multicolumn{6}{|c|}{ Description cover value Ident Accession } \\
\hline \multicolumn{6}{|c|}{ 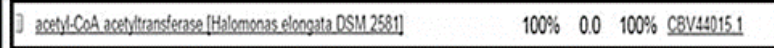 } \\
\hline \multicolumn{6}{|c|}{ 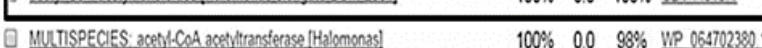 } \\
\hline \multicolumn{2}{|l|}{0 acety-CoA acetytransterase [Halomonas sinaiensis] } & $100 \%$ & 00 & $98 \%$ & WP 0647005381 \\
\hline \multicolumn{2}{|l|}{ 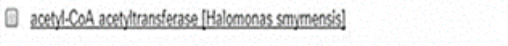 } & $100 \%$ & 0.0 & $91 \%$ & WP 0168539701 \\
\hline \multicolumn{2}{|l|}{ Q acety-CoA acetitunsterase [Halomonas shengiensis] } & $100 \%$ & 0.0 & $92 \%$ & $\underline{\text { S0045355.1 }}$ \\
\hline \multicolumn{2}{|l|}{ Q acety-COA acetitunnserase [Halomonas SO PBN3] } & $100 \%$ & 0.0 & $91 \%$ & WP 0230050101 \\
\hline \multicolumn{2}{|l|}{ (-) acetv-COA acetytransferase [Halomonasso HGO1] } & $100 \%$ & 0.0 & $90 \%$ & WP 0.550793671 \\
\hline \multicolumn{2}{|l|}{ 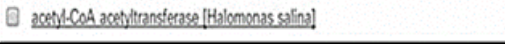 } & $100 \%$ & 0.0 & $90 \%$ & WP 035592997.1 \\
\hline
\end{tabular}

(b)

FIGURE 4 (a) The BLASTN result of the phbA gene and (b) the BLASTP result of PhbA. 


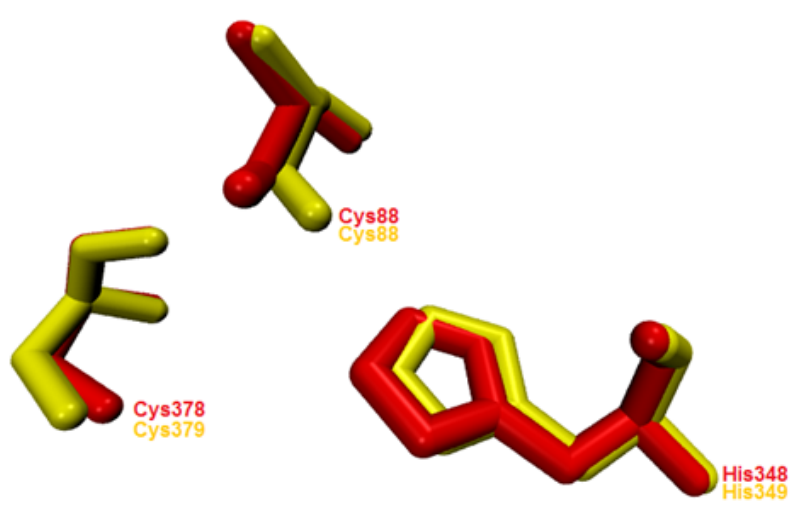

FIGURE 5 Prediction of PhbA 3D structure using I-TASSER. Residues in red color are PhbA and yellow are RePhbA.

\section{Authors' contributions}

RH designed the study. Molecular cloning strategy was led by ER. NPY carried out the laboratory work. ER, RH, NPY analyzed the data and prepared the manuscript. All authors read and approved the final version of manuscript.

\section{Competing interests}

The authors declare no competing interest.

\section{References}

Colwill JA, Wright EI, Rahimifard S. 2012. A holistic approach to design support for bio-polymer based packaging. J Polym Environ. 20(4):1112-1123. doi:10.1007/s10924-012-0545-z.

Dietrich D, Illman B, Crooks C. 2013. Differential sensitivity of polyhydroxyalkanoate producing bacteria to fermentation inhibitors and comparison of polyhydroxybutyrate production from Burkholderia cepacia and Pseudomonas pseudoflava. BMC Res Notes 6:219. doi:10.1186/1756-0500-6-219.

Hertadi R, Kurnia Kurnia WF, Puspasari M. 2017. Polyhydroxybutyrate (PHB) production by Halomonas elongata BK-AG18 indigenous from salty mud crater at Central Java Indonesia. Malays J Microbiol. 13(1):2632.

Jari M, Khatami SR, Galehdari H, Shafiei M. 2015. Cloning and expression of poly 3-hydroxybutyrate operon into Escherichia coli. Jundishapur J Microbiol. 8(2):1-4. doi:10.5812/jjm.16318.

Kim EJ, Kim KJ. 2014. Crystal structure and biochemical characterization of PhaA from Ralstonia eutropha, a polyhydroxyalkanoate-producing bacterium. Biochem Biophys Res Commun. 452(1):124-129. doi:10.1016/j.bbrc.2014.08.074.

Klijn N, Weerkamp AH, de Vos WM. 1991. Identification of mesophilic lactic acid bacteria by using polymerase chain reaction-amplified variable regions of 16s rRNA and specific DNA probes. Appl Environ Microbiol. 57(11):3390-3393.
Modis Y, Wierenga RK. 2000. Crystallographic analysis of the reaction pathway of Zoogloea ramigera biosynthetic thiolase. J Mol Biol. 297(5):1171-1182. doi:10.1006/jmbi.2000.3638.

Muangsuwan W, Ruangsuj P, Chaichanachaicharn P, Yasawong M. 2015. A novel nucleic lateral flow assay for screening of PHA-producing haloarchaea. J Microbiol Methods 116(Supplement C):8-14. doi:10.1016/j.mimet.2015.06.012.

Sambrook J, Russell DW. 2001. Molecular cloning: a laboratory manual. Cold Spring Harbor, NY: CSHL Press.

Singh R. 2014. Isolation and characterization of efficient poly-hydroxybutyrate (PHB) synthesizing bacteria from agricultural and industrial land. Int J Curr Microbiol App Sci. 3(6):304-308. 